\title{
ANALYSIS OF THE RELATIONSHIP BETWEEN INCOME GROWTH AND, COAL CONSUMPTION AND EMISSIONS FROM NONLINEAR PERSPECTIVE
}

\author{
Emrah Bese, Corpus Christi, Texas, U.S.A. \\ H. Swint Friday, Texas A\&M University - RELLIS, U.S.A. \\ Marilyn Spencer, Texas A\&M University - Corpus Christi, U.S.A.
}

dx.doi.org/10.18374/JABE-21-1.5

\begin{abstract}
In this study, Brazil, Turkey, Australia, Estonia, South Africa (SA), Finland and Sweden are examined by Autoregressive Distributed Lag model (ARDL), non-linear ARDL (NARDL) and Gregory-Hansen (GRHA) cointegration models for the relationship between emissions and growth, and coal consumption (CCSP) and growth. For emissions and growth relationship, environmental Kuznets curve (EKC) is investigated. For coal CCSP and growth relationship, CCSP EKC is investigated.For Brazil and Turkey, external debt does not have a significant effect on emissions in the long run. For Australia and Finland, EKC is not confirmed. For Estonia, EKC is not confirmed by ARDL model, and no asymmetric relationship is found between emissions and growth by NARDL model. For SA, no asymmetric relationship between emissions and growth is found by NARDL model. The EKC hypothesis and CCSP EKC are not confirmed for the countries that are included in this study. Although Sweden put great effort to eliminate coal consumption for energy production, CCSP EKC is not confirmed for Sweden in this study. Australia's coal market and renewable energy policies for coal consumption may be an example for the other countries which try to eliminate coal consumption for energy production such as Sweden in this case.
\end{abstract}

Keywords: coal consumption environmental Kuznets curve; Finland; Sweden; NARDL model 